\title{
A Study about the Analysis of Nonintellectual Acting Factors and Strategies Improving of College Students' Self-Regulated Learning
}

\author{
Jian-Hong LU \\ Department of Life Sciences and Technology, Shaanxi Xueqian Normal University, Shaanxi, China; \\ azurelu2008@163.com
}

Keywords: Self-regulated Learning, Nonintellectual acting factors, Effective strategies.

\begin{abstract}
Self-regulated Learning is a newly forming learning theory which is based on Humanistic Psychology. The learners follow their actual situation to decide their learning contents, learning targets and self-control the learning process, self-evaluate the learning efficiency. The whole process is a theoretical model of realizing the autopsychic and autonomic learning. The Nonintellectual Acting Factors of college students, such as, Self-efficacy, Attribution, Motivation, and Self-concept are the most important and direct factors. Therefore, how to evaluate and control the nonintellectual acting factors of the college students' learning process is the critical point of acquiring the scholastic achievement. It is still the key point of this psychology research.
\end{abstract}

\section{Introduction: the Concept of Self-Regulated Learning}

American famous professor of psychology, Barry Zimmerman, posted that Self-regulated learning emphasizes autonomy and control by the individual who monitors, directs, and regulates actions toward goals of information acquisition, expanding expertise, and self-improvement in $1989^{[1]}$. Paul Pintrich the American professor of University of Michigan indicated specifically for the self-regulating learning was a learning process of self-guiding and self-construction in $2000^{[2]}$. While Chinese main research of Self-regulating Learning is from 1970s. Most scholars of China pay more attention to longitudinal dimension and lateral dimension on the concept of self-regulating learning. They emphasize the natural interpretation of all the activities in longitudinal research. And people emphasize to definite the conception of the self-regulating learning from many perspectives in cross-sectional research. From the research contents and process of Self-regulating Learning in China and western countries, we know that the commonness of them is the self-regulation and self-evaluation in cognition, consciousness, motivation and behaviors.

Self-regulated Learning is a newly forming learning theory which is based on Humanistic Psychology. With the tutors' guidance, learners set up the learning contents, learning sites, learning methods and learning targets according to their own situation. They can regulate the learning process and evaluate the learning achievement to realize the aim of self-regulation. The essence of self-regulating learning is to guide the teachers or tutors to help learners to learn more quickly and more efficiency with various teaching methods. There are three more important advantages about Self-regulated Learning. First one is to making up for the defects of regular training classes in time and space resources. Second one is that the process is the second integration of teaching and learning. The third one is to stimulating learners' interest, learning engagement and learning motivation.

\section{The Analysis of Nonintellectual Acting Factors on Self-regulated Learning of College Students}

The intrinsic drive of affecting Self-regulated Learning is intelligence factors and nonintellectual factors. Intelligence factors are usually with abstract thinking as the core, just as the sense, perception, reasoning, memory and so on. Nonintellectual factors mainly include self-efficacy, attribution, attitude and motivation, learning strategies and other personal factors. All of the factors play an important role in motivating college students' learning enthusiasm and exploring their learning potential. To some extent, learners' nonintellectual factors are foremost and direct acting factors. 
This paper focuses on the promotion of the self-regulated learning ability in nonintellectual factors, to explore the efficient strategies of college students.

\section{The First Nonintellectual Acting Factor is Self-Efficacy.}

The American Scholar, Albert Bandura, put forward that self-efficacy is the embodiment of individual ability self-confidence in some activities, that is, individuals believe that they have the ability to complete an activity. The cognitive psychology school thinks that self-efficacy is the important influenced variable of Self-regulated Learning. Self-efficacy affects the definition of self-regulated learning targets, through the influence of learning strategies. College students' self-efficacy, which is the evaluation of their own many factors, is the critical point to determine their ability to get academic achievements or not. For one thing, self-efficacy affects college students to choose their targets of Self-regulated Learning. In freely situation, college students tend to choose to complete the easy task, and to avoid some difficult tasks. For another, self-efficacy affects the determining of the learning goals in Self-regulated Learning ${ }^{[3]}$. The college students with high self-efficacy tend to choose the challenging tasks. Frustration in learning is easier to stimulate their spirit and perseverance, and constantly enhance their social adaptability. Last but not least, self-efficacy affects the application of learning strategies in college students' learning activities.

\section{The Second Nonintellectual Acting Factor is Attribution.}

Attribution refers to the explanation of the individual's success or failure. There are attributions of the internal and external two points. Weiner, a famous American psychologist, proposed that the common learner attributes his success to four factors: ability, effort, task difficulty and luck. Ability is a stable and internal factor, effort is an unstable and internal factor. The difficulty of the targets is a stable, external factor and luck is an unstable, external factor. People whom with the internal factor, is usually attributed to the ability of their success and attributed to their fun-enough effort of their failure. People whom with the external factor, is usually attributed to the outside causes of their success and failure. Self-regulated Learning has a correlation with the internal and external attribution, that is to say, Learners with external attribution weaken their initiative and creativity, and external attribution has certain effect on the independent learning. Learners with internal attribution are capable of consciousness to their value, and enhance their sense of self-efficacy. When facing to their learning frustration, they can stimulate the stronger learning motivation to improve their autonomous learning efficiency.

\section{The Third Nonintellectual Acting Factor is Self-Concept.}

William. James, an American scholar put forward that self-concept is a structure to be used to predict and presume human behaviors. It is the interaction between the learners and the social environment through its acquisition of experience to set up self-perception. Scholars in our country Jing-qiong Wang and other professors proposed that self-concept was positively correlated with Self-regulated Learning. Using learning attribution and the adaptation of the environment as the media, the self-concept of learners can affect the learning achievement. A series of behaviors of Self-judge, Self-observation and Self-response are accompanied by the self-concept, at the same time, they also have a corresponding impact on Self-regulated Learning. Self judgment is the behavioral reaction of the learners after comparing their learning results and learning targets. They can effectively improve learners' self-efficacy by the systematic training of the Self-judge. Self observation is the learner to observe and monitor of the self-regulated learning process, it can control the learning process, providing the completion of the learning targets ${ }^{[4]}$. Self-response is the reaction of learners to their learning achievement. Positive self-response can promote self-regulated learning, while negative self-response would hinder the college students' tentative learning activities. 


\section{Strategies of Improving the College Students’ Ability of Self-Regulated Learning}

Learning strategies are various learning schemes which proposed consciously by learners to increase their learning effectiveness. The domestic and foreign scholars have conducted in-depth research on many aspects of learning strategies, on the theoretical basis of the American scholar Chamot and $\mathrm{O}$ - Malley, the learning strategies are divided into meta-cognitive strategies, cognitive strategies and affective strategies. Meta-cognitive strategies are the learners to manage their learning strategies about their learning process by self-monitoring, self planning and self evaluation ${ }^{[5]}$. Cognitive strategies are the specific steps and methods for learners to be used to complete certain task. Affective strategies are the social strategies which learners use to communicate with others. Its scope of application is not limited to the learning process, at same time, using language acquisition to communicate graceful with others is a kind of effective learning strategies. All these three kinds of learning strategies can help learners to learn actively.

\section{Fostering Diversified Learning Strategies.}

The famous expert Oxford posted that the training of learning strategies involves six steps. First is to determine the learning motivation and learning time. Second is to choose the efficient learning strategies. Third is to outline overall the training process of the learning strategies. Fourth is to carry out the plan of the learning strategies. Fifth is to evaluate the training process of learning strategies in detail. Six is to correct and improve of learning schemes. Using Oxford training methods and combined with the specific characteristics of Chinese college students, learning strategy training is divided into three ways, that is short-term training, medium-term training, and long-term training. This paper is mainly to make a questionnaire about the first grade students in Shaanxi Xueqian Normal University, focus on the analysis of college students' self-regulated learning motivation and self-efficacy. The questionnaire is in the form of E-mail on the Internet, so that the survey data college students can reflect the situation of the college students objectively. According to the result of the questionnaire, we try to help college students to create flexible and effective extra-curricular learning plans. According to different cognitive styles of different individuals to make the specific training plan, which adopts class training and break training. The critical training process is to mobilize the learning enthusiasm and initiative of college students in the choice of different strategies, through the satisfying of the instrumental motivation to stimulate its integrative motivation. College students can try to establish a learning community over the Internet, through which they can communicate the learning strategies with other students. The interaction of the teachers and students can be maintained by the face-to-face teaching or internet teaching patterns, also that, teachers and students usually make the reflection and summary of learning strategies to correct and improve the unsuitable learning strategies and methods.

\section{Stimulating and Developing the Good Learning Habits.}

Teachers in college should focus on the individual differences of the students, and make the face-to-face guidance to help students find the learning strategies suited to their own characteristics. This requires teachers not only to carry out activities of guidance, monitoring, diagnosis and evaluation, but also to make the follow-up survey of students regularly so as that tutors give learners the corresponding learning strategies. University teachers, counselors and professional teachers can try to understand the real reasons of their passive learning by the way of questionnaires and individual interviews, through which to guide the college students to cultivate the self-regulated learning consciousness. University teachers encourage students to learn self-regulated should pay attention to four points. First is to guide students to sort out the interdepartmental relations of the short-time learning plan and the required knowledge of the syllabuses to master. Second is to strengthen college students' ability of using the scientific methods and to arrange the learning time reasonably. Third is to pay great attention to cultivate of the self examining ability and the self evaluating ability. Fourth is to help students to get the consciousness of the knowledge transformation with the retrospective 
method and the introspective method. Teachers can monitor learning effect, learning schedule and learning quality of students flexibly to help them form good learning habits.

\section{Carrying Out the Cooperative Learning Under the Self-Regulated Learning}

The famous American scholar Rilly proposed that self-regulated learning is not only applied to the learning individuals, but also applied to learning groups. Therefore, it makes the cooperative learning of self-regulated learning be a reality. Cooperative learning is a teaching theory or a strategy, which is to assist learning individuals help others in heterogeneous groups and get the aim of the learning targets. ${ }^{[6]}$ Cooperative learning originated from the students dynamical study in 1960s by sociologists. The theoretical bases are the cognitive theory, cybernetics, group dynamics theory and teaching theory. It is not difficult to find that cooperative learning and self-regulated learning are seemingly contradictory, but in fact, they are similiar. Therefore we attempt to obtain a new learning effect with the combination of cooperative learning and self-regulated learning. The test operation is as follows.(1)Group principle: it means to sort the learners with different cognitive styles into a group so as to achieve the complementary and mutual assistance among heterogeneous members. (2)Communicate activity: it means to encourage learners to Email tutors and teachers when they meet the problems of learning and emotional attitudes. Tutors can make a statistical analysis every two weeks to solve all kinds of emerging problems according to their different patterns and hierarchies. (3)Evaluation criterion: it means to grade the completing groups for cultivating and improving the students' confidence and sense of responsibility. (4)Monitoring mechanism: it means to ask the group to make the macro and micro plans before training, and inspect their completeness of the plans irregularly for finding and solving their problems. (5) Incentive mechanism: it means to make the material incentives for the groups which complete the tasks swiftly, at the same time, stimulate the competition of the homogeneous groups and improve the cooperation of the heterogeneous groups.

\section{Conclusion}

In conclusion, the regulated learning ability of college students can be cultivated and improved by learning and training, mainly rely on the shared physical resources and learning environment of tutors and learners to creat a harmonious, open, mutual respect, equality and cooperation learning atmosphere. At the same time, we should pay more attention to nonintellectual acting factors of self-regulated learning to imorove their self-efficacy sense, internal attribution, motivation and self-concept ability, to cultivate the diversified self-regulated learning strateyies and to form the good self-regulated learning habits, strengthern the cooperative abilities so as to improve the multi-lever, multi-aspest and multi-factor self-regulated learning ability.

\section{Acknowledgement}

This research was financially supported by the Educational Science Research Project of Shaanxi Province (SGH140703) and the Science Research Project of Shaanxi Xueqian Normal University (2016YBKJ066).

\section{References}

[1] Zimmerman B.J.\& D.H. Schunk.: Self-Regulated Learning and Acadamic Achievement Springer Verlag.1989.

[2] Pintrich, P. R. \& Schunk, D. H. (2000). Motivation in education: Theory, research, and applications. Upper Saddle River, NJ: Merrill-Prentice Hall. 
[3] Butler, D.L., Cartier, S.C., Schnellert, L., Gagnon, F. \& Giammarino, M.: Secondary students’ self-regulated engagement in reading: researching self-regulation as situated in context. Psychol Test Assess Model, 53 (1), 161-179.

[4] Perry, N.E., Phillips, L., \& Hutchinson, L.R. (2006). Preparing student teachers to support for self-regulated learning. Elementary School Journal, 106, 237-254.

[5] Laskey, M.L., \& Hetzel, C.S. (2010). Self regulated learning, metacognition and soft skills: the 21st century learner.

[6] Winne, P.H. \& Perry, N.E. (2000). Measuring self-regulated learning. In P. Pintrich, M. Boekaerts, \& M. Seidner (Eds.), Handbook of self-regulation (p. 531-566). Orlando, FL: Academic Press.

[7] Whyte, Cassandra Bolyard, "Effective Counseling Methods for High-Risk College Freshmen", Measurement and Evaluation in Guidance, 10, 4, January 1978, 198-200.

Winne, P.H.: Bootstrapping learner's self-regulated learning. Psychol Test Assess Model, 52 (4).

[8] Winne, P.H. \& Hadwin, A.F. The Weave of Motivation and Self-Regulated Learning.In Schunk, D.H., \& Zimmerman, B.J. (2008), Motivation and Self-Regulated Learning: Theory, Research, and Application (pp. 297-314). New York, NY: Routledge.

[9] Winne, P.H. \& Perry, N.E. (2000). Measuring self-regulated learning. In P. Pintrich, M. Boekaerts, \& M. Seidner (Eds.), Handbook of self-regulation (p. 531-566). Orlando, FL: Academic Press.

[10] Ziegler, A., Stoeger, H. \& Grassinger, R. (2011). Actiotope model and self-regulated learning. Psychol Test Assess Model, 53 (1), 141-160. 